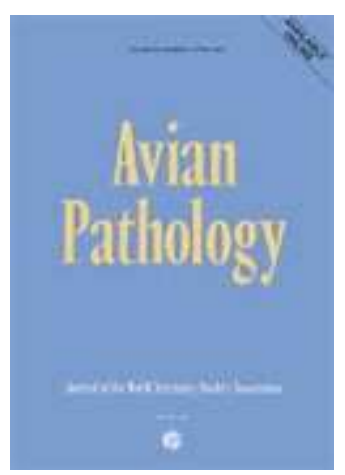

\title{
Turkey rhinotracheitis outbreak caused by the environmental spread of a vaccine derived avian metapneumovirus
}

\begin{tabular}{|c|c|}
\hline Journal: & Avian Pathology \\
\hline Manuscript ID: & CAVP-2011-0039.R2 \\
\hline Manuscript Type: & Original Research Paper \\
\hline $\begin{array}{r}\text { Date Submitted by the } \\
\text { Author: }\end{array}$ & 29-Jun-2011 \\
\hline Complete List of Authors: & $\begin{array}{l}\text { Lupini, Caterina; University of Bologna, Dipartimento di Scienze } \\
\text { Mediche Veterinarie } \\
\text { Cecchinato, Mattia; Faculty of Veterinary Science, Dipartimento di } \\
\text { Sanità Pubblica, Patologia Comparata e Igiene Veterinaria } \\
\text { Ricchizzi, Enrico; University of Bologna, Dipartimento di Scienze } \\
\text { Mediche Veterinarie } \\
\text { Naylor, Clive; University of Liverpool, Department of Infection } \\
\text { Biology } \\
\text { Catelli, Elena; University of Bologna, Dipartimento di Scienze } \\
\text { Mediche Veterinarie }\end{array}$ \\
\hline Keywords: & Avian metapneumovirus, reversion to virulence, vaccine, TRT \\
\hline
\end{tabular}

\section{SCHOLARONE Manuscripts}


CAVP-2011-0039. R2

A Turkey rhinotracheitis outbreak caused by the environmental spread of a vaccine derived avian metapneumovirus

Caterina Lupini $^{1 *}$, Mattia Cecchinato ${ }^{2}$, Enrico Ricchizzi ${ }^{1}$, Clive J. Naylor ${ }^{3}$, Elena Catelli $^{1}$

${ }^{1}$ Dipartimento di Scienze Mediche Veterinarie, Alma Mater Studiorum - University of Bologna, Via Tolara di Sopra, 50, 40064 Ozzano Emilia (BO), Italy; ${ }^{2}$ Dipartimento di Sanità Pubblica, Patologia Comparata e Igiene Veterinaria, Faculty of Veterinary Medicine, University of Padua, Viale dell'Università, 16, 35020 Legnaro (PD), Italy;

${ }^{3}$ Department of Infection Biology, Institute of Infection and Global Health, Faculty of Health and Life Sciences, Leahurst Campus, University of Liverpool CH64 7TE, United Kingdom.

Short Title: Environmental spread of a vaccine derived aMPV

Received: 29 June 2011

"Corresponding Author: Caterina Lupini,

Tel.+39051 2097080.Fax.+39051 2097039.Email: caterina.lupini@unibo.it 


\begin{abstract}
Avian metapneumovirus (aMPV) subtype A was isolated from seven-week-old turkeys showing respiratory disease typical of turkey rhinotracheitis (TRT). Comparison of the virus sequence to previously determined vaccine marker sequences showed that the virulent virus had originated from a licensed live subtype A aMPV vaccine. The vaccine had neither been in use on the farm within a period of at least six months nor had it been used on farms within a distance of approximately five kilometres. Isolation of the virus and exposure to naive turkeys caused disease typical of a virulent aMPV field strain. The study shows that disease was caused by exposure to aMPV vaccine-derived virus which was present in the environment and indicates that such virus is able to circulate for longer than was previously envisaged.
\end{abstract}




\section{Introduction}

Avian metapneumovirus (aMPV) causes an upper respiratory tract infection in turkeys and in some other avian species, including chickens. In laying or breeding birds the virus can cause drops in egg production and poor eggshell quality. These conditions are associated with serious economic losses in unprotected birds especially when secondary pathogens become involved (Cook, 2000; Gough \& Jones, 2008). aMPV is classified in the genus Metapneumovirus, family Paramyxoviridae (Pringle, 1998), and contains a non-segmented genome, negative stranded RNA of approximately 13,500 nucleotides, containing 8 genes (3'-N-P-M-F-M2-SH-G-L-5'), currently believed to code for nine proteins (Easton et al., 2004). aMPVs are grouped in four subtypes (A, B, C and D) based on nucleotide sequence differences (Juhasz \& Easton, 1994; Bayon-Auboyer et al., 2000; Seal et al., 2000). A and B subtypes have been prevalent in Europe since its first appearance (Hafez et al., 2000; Jones, 2010).

The first aMPV virus isolation in Italy was made in 1987 (Fabris \& D'aprile, 1990). Since 2001, subtype B field viruses were frequently found in the most poultry populated areas in the North of Italy using sporadic and longitudinal, virological and molecular testing of turkeys and chickens (Catelli et al., 2004a; b; Catelli, 2006; Catelli et al., 2010; Terregino, 2010). In general, subtype B vaccines were used for its control, although subtype A vaccine has also been used, but to a more limited degree from approximately 2002. At this time no subtype A virus had been detected in the field in Italy. Although Italian subtype B viruses have been widely studied (Catelli et al., 2010; Cecchinato et al., 2010) less information has been available for Italian aMPV A subtypes. In the only published study, disease was observed at 3 weeks of age which was shown to be caused by a vaccine derived revertant virus (Catelli et al., 
2006) and in that instance, the flocks had been vaccinated at one day of age with the same live subtype A vaccine.

We now report details of another Italian subtype A aMPV isolated during a turkey rhinotracheitis (TRT) outbreak on a large farm of seven-week-old male turkeys which had only been vaccinated with subtype B vaccine at seven days of age.

\section{Materials and Methods}

Farm. Samples were collected during an outbreak of respiratory disease from a farm of approximately 20,000 male turkeys in a lowly populated poultry area (Umbria Region), belonging to an Italian integrated poultry company. Clinical signs started when turkeys were 45 days of age and were characterized by sneezing, ocular discharge and nasal exudate. Mortality reached $10-11 \%$. All the birds were vaccinated by eye drop administration at seven days of age with a live aMPV subtype B vaccine. Subtype A vaccine was not in use and had not been in use for at least six months in other turkey farms within a distance of approximately five $\mathrm{km}$. Within that distance, all turkey farms belonged to the same poultry company and were subjected to the same vaccination scheme. Therefore subtype A vaccine was not in use in the locality.

Sampling. At seven weeks of age, when clinical signs were first observed, 15 birds were oro-pharingeally swabbed for virus isolation. Swabs were pooled into serum free Minimal Essential Medium (Invitrogen, Scotland) with antibiotics to suppress bacterial and Mycoplasma growth, kept refrigerated during transportation then stored at $-80^{\circ} \mathrm{C}$ until processing. 
aMPV isolation. Virus isolation was performed in chicken embryo tracheal organ cultures (TOC) (Cook et al., 1976). The swabs pool was centrifuged at $1000 \mathrm{~g}$ for 10 min. at $+4^{\circ} \mathrm{C}$. The supernatant was used to inoculate TOCs after filtration through $0.45 \mu \mathrm{m}$ membrane filters. Ciliostasis was taken as the initial indicator of aMPV detection. RNA was extracted from the TOCs (QIAamp viral mini kit, Quiagen) and subsequent RT-PCR was used to confirm virus presence and to determine the subtype.

RT- PCR and sequencing. RNA was typed using a subtype specific RT-nested PCR based on AMPV attachment $(G)$ gene sequence which was able to differentiate A and B subtypes (Cavanagh et al., 1999). Wizard® SV Gel and PCR Clean-Up System (Promega) was used for amplicon purification. Sequencing was performed at BMR Genomics (Padua, Italy) with the 3730x1 DNA Analyzer (Applied Biosystems, USA).

\section{Comparison to available subtype A AMPV G gene sequences and phylogenetic}

analysis. The partial $\mathrm{G}$ gene sequence (268 bp) of the isolated virus was compared to available sequences. Two live subtype A aMPV vaccines were available in Italy, which had both been derived by empirical passage of the UK \#8544 strain. The sequence of vaccine 1 had been previously determined (Catelli et al., 2006), while the partial G gene sequence of vaccine 2 was determined using the method described above. Sequence of 309/04, a virulent revertant of vaccine 1, was also included (Catelli et al., 2006). The remainder of the sequences were sourced from GenBank and were: UK\#8544 (accession number: DQ666911.1), CVL/14/1 (accession number: L34032.1), LAH (accession number: AY640317.1), TRT/UK (accession number: S40185), 1556 (accession number: L34033), aMPV/A/Brazil/07/USP/03 
(EU140745.1), aMPV/A/Brazil/05/USP/01 (DQ786396), Chicken/A/BR/121/95

(Accession number: AY842243), Chicken/A/BR/119/95 (accession number:

DQ175635.1), aMPV/chicken/Nigeria/NI389/2006 (accession number: AM490057),

Brazil (accession number: AY739719.1), SHSBR669/03 (accession number:

AY739719.1), SHSBR662/03 (accession number: AY739717.1), SHSBR668/03

(accession number: AY739718.1).

Sequence comparisons were made using the CLUSTAL W web interface

(Larkin et al., 2007). Phylogenetic analysis was carried out under distance criterion, with neighbour-joining as algorithm, using MEGA4 software. Bootstrap values were obtained with 1,000 replicates.

Full genome sequencing and characterization of the aMPV isolate. The entire genome of the isolated virus was amplified and sequenced (GenBank accession number JF424833) as previously described (Naylor et al., 2004). This was compared using the CLUSTAL W web interface (Larkin et al., 2007) to the full sequence of vaccine 1 (Catelli et al., 2006), 309/04 strain (Catelli et al., 2006) and UK \#8544 strain (accession number DQ666911).

Partial sequencing of vaccine 2. Where vaccine 1 and UK\#8544 sequences differed (genome positions in antigenome sense: 2941, 3553, 3825, 5055 PubMed , 5140, $5929,6358,10022$ and 11624), the genome locations were sequenced in vaccine 2 using previously described methods (Catelli et al., 2006). These were compared to the homologous sequences of vaccine 1 and UK\#8544, using the CLUSTAL W web interface (Larkin et al., 2007) 
Virulence assessment of the aMPV isolate. The virulence of the isolated aMPV was determined by scoring clinical signs following eyedrop inoculation of 1-day-old poults. Thirty 1-day-old commercial turkeys were housed in three positive pressure isolators with 10 poults in each. Poults in isolator 1 were inoculated with the aMPV isolate at a dose of $3.5 \log _{10}$ median ciliostatic doses $\left(\mathrm{CD}_{50}\right)$ per bird. Poults in isolator 2 were inoculated with the vaccine 1 at a dose of $4.5 \log _{10}$ median tissue culture infectious doses $\left(\mathrm{TCID}_{50}\right)$ which represented a ten times overdose compared to the manufacturer's recommendations. Virus and vaccine 1 titres were calculated in TOCs and VERO cells respectively, using the method of Reed and Muench (Reed \& Muench, 1938). The third group was inoculated with sterile water and kept as the negative controls. Clinical signs were scored daily up to 14 days post infection as previously described (Naylor \& Jones, 1994). Briefly: 0. no clinical signs; 1. clear nasal exudate; 2. turbid nasal exudate; 3. swollen infra-orbital sinuses and/or frothy eyes. At the end of the trial all the birds were humanely killed.

The distribution of the clinical scores within the groups was first tested using the Kruskal-Wallis non parametric one-way ANOVA. The differences between groups were tested using the Mann-Whitney test. A p-value $<0.05$ was considered statistically significant.

\section{Results}

aMPV isolation. The ciliostatic agent isolated on TOCs was confirmed to be aMPV subtype A by RT nested PCR and was named IT/Ty/A/259-01/03. 


\section{Comparison to available subtype A aMPV G gene sequences and phylogenetic} analysis. Phylogenetic analysis carried out on partial G gene sequences (268bp) revealed that the strain IT/Ty/A/259-01/03 formed a separate cluster containing vaccine 1 and 309/04 (Figure 1), both derived from the UK\#8544 strain. No other sequence, including that of vaccine 2, which was also derived from the UK\#8544 strain, formed part of this cluster. At the detailed sequence level the vaccine 1, IT/Ty/A/259-01/03 and 309/04 strains possessed an exclusive cytosine residue at genome position 6358 which was a uracil in all the other strains with which it was compared (Table 1).

Full genome sequencing and characterization of the aMPV isolate. The complete sequencing of IT/Ty/A/259-01/03 showed that it possessed eight out of the nine nucleotide substitutions differentiating vaccine 1 and its progenitor, while the nucleotide at genome position 3553 occurring in the $\mathrm{F}$ gene matched the vaccine progenitor (Table 2). In addition there were four further mutations unique to IT/Ty/A/259-01/03 which occurred in the phosphoprotein $(\mathrm{P})$ gene, matrix protein (M) gene, G gene and polymerase (L) gene. These are highlighted in Table 2. Only the mutations in the $\mathrm{P}, \mathrm{M}$ and $\mathrm{F}$ genes coded for amino acid changes.

Partial sequencing of vaccine 2. Sequencing of UK\#8544 derived vaccine 2 showed that it shared none of the mutations resulting from the preparation of vaccine 1 from the same progenitor. It was identical to UK\#8544 in all nine positions.

Virulence assessment of aMPV isolate. Strain IT/Ty/A/259-01/03 caused disease when poults were inoculated under experimental conditions. The daily mean clinical 
score for each group is shown graphically in Figure 2. Virus IT/Ty/A/259-01/03 caused severe clinical signs in the inoculated birds from day four. Birds in the other two groups showed only very minor signs. The mean cumulative score was 15.4 in the IT/Ty/A/259-01/03 infected group and 1.54 and 0.64 respectively in the vaccine and uninoculated groups. A very highly significant statistical difference in clinical scores was found between the IT/Ty/A/259-01/03 inoculated group and the vaccine group $(\mathrm{U}=18531 ; \mathrm{p}<0.0001)$. There was also a significant difference between the IT/Ty/A/259-01/03 inoculated group and the uninoculated control group (U=18937; $\mathrm{p}<0.0001)$. The difference between the vaccine and uninoculated control group was not significant $(\mathrm{p}=0.125)$.

\section{Discussion}

For the first time, a virulent, vaccine-derived aMPV has been detected in turkeys to which the vaccine had not been administered. Sequencing showed that IT/Ty/A/25901/03 had derived from vaccine 1 , and experimental infection of naïve turkeys showed it to be virulent. Furthermore the virulent nature of the virus and the further mutations seen in addition to those characteristic of the vaccine, suggest that this was not a contamination of unpassaged vaccine as perhaps might occur due to personnel and fomite movement from premises contaminated following vaccine application. Vaccine 1 had not been applied on the farm either in that period, or for at least six months previously. Hence, at the very least, either the vaccine derived virus had persisted in the immediate environment for some period prior to its detection, or had 
been carried in as a contaminant in an already back-mutated form from sources further away, by feed trucks, other vehicles or personnel.

Field reversion to virulence of live vaccines is more likely to occur in avian than in other species because opportunities for horizontal transfer of vaccines are much increased due to the higher numbers of vaccinates. Convenience of mass live vaccine application increases the risk of vaccine virus circulation in birds. Also the precise nature of that application can have a bearing on persistence and disease. In a previous study, aMPV mass vaccine application by spray resulted in less than complete vaccine take, though unresponding birds did eventually receive virus, presumably due to bird to bird contact (Ganapathy et al., 2010). It is generally believed, and has been anecdotally demonstrated (Wilding P., personal communication) that in this incomplete vaccination scenario, reversion to virulence can be encountered and it was noticeable that many birds in the Ganapathy study only started to show vaccine replication at three weeks of age. In another example, reversion to virulence has almost certainly occurred after live infectious laryngotracheitis vaccine use and in some cases, current field strains appear to be their direct descendants (Oldoni et al., 2009; Moreno et al., 2010). In the light of these findings, the testing of genetic stability of avian vaccines during the live vaccine registration process could be considered to be of the highest priority. Where acceptable stability has not been obtained by conventional empirical passage, rational attenuation by reverse genetics may be required.

In a previous study aMPV vaccine virus revertant 309/04 was isolated and characterized from a farm where vaccine had been applied (Catelli et al., 2006). In the resultant discussion the view was taken that the revertant had probably arisen directly from the applied vaccine, but nonetheless it was accepted that it may have already 
been present in the environment. This was postulated because the five mutations, differentiating 309/04 from the vaccine seemed excessive to occur in just three weeks from vaccination. In the light of this information and the findings of the current study, it appears reasonable to conclude that both these revertant viruses deriving from vaccine 1 may have been present in the environment for some period prior to detection and isolation.

Circulation of aMPV vaccines in vaccinated or unvaccinated poultry flocks has been hypothesized, based on partial sequence analysis or epidemiological data (Banet-Noach et al., 2005; Chacon et al., 2007; Ongor et al., 2010). The complete sequencing of the IT/Ty/A/259-01/03 strain and comparison with vaccine and the vaccine progenitor showed the presence of eight out of the nine vaccine markers previously reported (Catelli et al., 2006). These mutations uniquely arose during the generation of vaccine 1 by passage of \#8544, primarily in Vero cells. A simplistic calculation of permutations, where 13,373 genome bases could have one of 4 identities, shows that the probability of achieving the vaccine sequence by random mutation of a field strain would be 1 in $4^{13,373}$ or $10^{2,012}$. In reality, mutation of most nucleotides would not result in viable virus hence this probability would actually be higher, though remain tiny. Furthermore, when another aMPV subtype A field strain was grown in Vero cells, none of the vaccine marker mutations were found (Naylor et $a l, 2004)$. This indicates that the marker mutations were not automatically generated simply by adaptation to Vero cell culture. By any reasonable assessment the isolated virus was without any doubt whatsoever, of vaccine origin. There can be no doubt that IT/Ty/A/259-01/03 and by similar argument 309/04, had derived from vaccine 1 . In further support of this point, vaccine 2 which also derived via cell culture from the 
same UK\#8544 progenitor, though not in Vero cell culture shared none of the nine mutations which arose during the generation of the otherwise similar vaccine 1 . It can be deduced that the five mutations occurring during the field passage of vaccine 1 are responsible for the observed increase in virulence. None of the mutations occurred in recognized transcription controlling regions, hence only the coding changes in $\mathrm{P}, \mathrm{M}$ and $\mathrm{F}$ genes are likely to have affected the phenotype. It is tempting to hypothesize that the mutation at genome position 3553, resulting in a predicted amino acid substitution in the F protein, is likely to have been of most significance because this had been mutated in the generation of the vaccine from UK\#8544 and then back mutated during field passage. However consideration of the nature of the amino acid substituted makes this less likely because the V residue found in UK\#8544 and in the revertant is of similar character to the A found in vaccine 1 . Nonetheless the effects of this substitution may still remain significant. On the other hand, the A to $\mathrm{E}$ and $\mathrm{S}$ to $\mathrm{Y}$ predicted substitutions in the $\mathrm{P}$ and $\mathrm{M}$ proteins respectively are likely to be more influential because they represent charge and size differences which have greater potential to change protein properties. To determine which mutations increased the virulence, individual mutations would need to be made by reverse genetics as carried out for 309/04 in a previous study (Brown et al., 2011). Whichever of these mutations eventually prove responsible for the virulence increase, it is interesting to make comparison with 309/04 because in that instance virulence was conclusively demonstrated to arise from a charged amino acid substitution in the polymerase gene. It therefore seems likely that reversion and attenuation might result from changes in any of a number, or possibly all, of the aMPV genes.

A further finding of this study is its confirmation of the limitations of cross protection between subtypes. Van de Zande et al. (2000) showed that the duration of 
heterologous protection declined while homologous protection was maintained. In this instance, the A subtype virus was found some six weeks after vaccination at a time when heterologous protection might have critically deteriorated.

The initial G gene sequencing, which showed the difference between vaccine, the progenitor and available sequences for numerous international subtype A aMPVs at genome position 6358 , conveniently fell within the genomic region amplified by two commonly used diagnostic RT-PCR protocols (Bayon-Auboyer et al., 1999; Cavanagh et al., 1999). Sequencing of this fragment during future routine diagnostic studies will give some indication of whether vaccine 1 or its revertants were present. Based on the data currently available in Italy, and bearing in mind the relatively low number of subtype A viruses detected, it would currently be possible to hypothesize that most or all subtype A isolations have arisen from the spread of subtype A vaccine. Because the 6358 mutation occurs in this commonly used RT-PCR region, it would be relatively easy to sequence available amplicons to disprove or add weight to this notion. A similar single one base mutation approach has been conveniently used previously to distinguish between subtype B aMPV field viruses and vaccine and this was able to be coupled to a restriction endonuclease digestion for rapid differentiation (Lupini et al., 2010).

The study again highlights, and this time with perhaps greater urgency, the need for live aMPV vaccines that do not revert to virulence. It is generally, and probably correctly, believed that aMPV vaccine reversion to virulence is a rare event and also one which can be avoided by stringent vaccine application. The current study highlights the possibility that even where a farm follows such stringent procedures they may still be vulnerable from other farms working to a lower application standard. 


\section{References}

Banet-Noach, C., Simanov, L. \& Perk, S. (2005). Characterization of Israeli avian metapneumovirus strains in turkeys and chickens. Avian Pathology, 34, 220226.

Bayon-Auboyer, M.H., Arnauld, C., Toquin, D. \& Eterradossi, N. (2000). Nucleotide sequences of the $\mathrm{F}, \mathrm{L}$ and $\mathrm{G}$ protein genes of two non-A/non-B avian pneumoviruses (APV) reveal a novel APV subgroup. Journal of General Virology, 81, 2723-2733.

Bayon-Auboyer, M.H., Jestin, V., Toquin, D., Cherbonnel, M. \& Eterradossi, N. (1999). Comparison of F-, G- and N-based RT-PCR protocols with conventional virological procedures for the detection and typing of turkey rhinotracheitis virus. Archives of Virology, 144, 1091-1109.

Brown, P.A., Lupini, C., Catelli, E., Clubbe, J., Ricchizzi, E. \& Naylor C.J. (2011). A single polymerase (L) mutation in avian metapneumovirus increased virulence and partially maintained virus viability at an elevated temperature. Journal of General Virology, 92, 346-354.

Catelli, E., Cecchinato, M., Delogu, M., De Matteo, P., Ortali, G., Franciosi, C., De Marco, M.A. \& Naylor, C.J. (2004a). Avian Pneumovirus infection in turkey and broiler farms in Italy: a virological, molecular and serological field survey. Italian Journal of Animal Science, 3, 286-292.

Catelli, E., Cecchinato, M., Ortali, G., De Matteo, P., Savage, C.E., Jones, R.C. \& Naylor C.J. (2004b). Avian Pneumovirus in Italy. In: Proceedings of IV International Symposium on avian corona- and Pneumovirus Infections, - 
Rauischholzhausen. Germany: eds: E.F. Kaleta \& U. Heffels-Redmann, pp. $275-281$.

Catelli, E. (2006). Dati epidemiologici sulle infezioni da Pneumovirus Aviare in Italia. Atti del convegno Malattie virali respiratorie e problemi di produzione (pp.16-23). Bologna, Italy.

Catelli, E., Cecchinato, M., Savage, C.E., Jones, R.C. \& Naylor, C.J. (2006). Demonstration of loss of attenuation and extended field persistence of a live avian metapneumovirus vaccine. Vaccine, 24, 6476-6482.

Catelli, E., Lupini, C., Cecchinato, M., Ricchizzi, E., Brown, P. \& Naylor, C.J. (2010). Field avian metapneumovirus evolution avoiding vaccine induced immunity. Vaccine, 28, 916-921.

Cavanagh, D., Mawditt, K., Britton, P. \& Naylor, C.J. (1999). Longitudinal field studies of infectious bronchitis virus and avian pneumovirus in broilers using type-specific polymerase chain reactions. Avian Pathology, 28, 593-605.

Cecchinato, M., Catelli, E., Lupini, C., Ricchizzi, E., Clubbe, J., Battilani, M. \& Naylor, C.J. (2010). Avian metapneumovirus (AMPV) attachment protein involvement in probable virus evolution concurrent with mass live vaccine introduction. Veterinary Microbiology, 146, 24-34.

Chacon, J.L., Brandao, P.E., Buim, M., Villarreal, L. \& Ferreira, A.J. (2007). Detection by reverse transcriptase-polymerase chain reaction and molecular characterization of subtype B avian metapneumovirus isolated in Brazil. Avian Pathology, 36, 383-387.

Cook, J.K. A. (2000). Avian pneumovirus infections of turkeys and chickens. Veterinary Journal, 160, 118-125. 
Cook, J. K. A., Darbyshire, J.H. \& Peter, R.W. (1976). The use of chicken tracheal organ cultures for the isolation and assay of avian infectious bronchitis virus. Archives of Virology, 50, 109-118.

Easton, A.J., Domachowske, J.B. \& Rosenberg, H.F. (2004). Animal pneumoviruses: molecular genetics and pathogenesis. Clinical Microbiology Reviews, 17, 390412.

Fabris, G. \& D'aprile, P.N. (1990). Rinotracheite infettiva del tacchino: osservazioni sul campo ed indagini di laboratorio. Zootecnica International, 6, 36-40.

Ganapathy, K., Bufton, A., Pearson, A., Lemiere, S. \& Jones, R.C. (2010).

Vaccination of commercial broiler chicks against avian metapneumovirus infection: a comparison of drinking-water, spray and oculo-oral delivery methods. Vaccine, 28, 3944-3948.

Gough, R.E. \& Jones, R.C. (2008). Avian Metapneumoviruses. In Y.M. Saif, A.M. Fadly, J.R. Glisson, L.R. McDougald, L.K Nolan \& D.E. Swayne (Eds). Diseases of Poultry $12^{\text {th }}$ edn (pp. 100-110). Ames: Blackwell Publishing.

Hafez, H.M., Hess, M., Prusas, C., Naylor, C.J. \& Cavanagh, D. (2000). Presence of avian pneumovirus type A in continental Europe during the 1980s. Journal of Veterinary Medicine. B, Infectious Diseases and Veterinary Public Health, 47, 629-633.

Jones, R.C. (2010). Viral respiratory diseases (ILT, aMPV infections, IB): are they ever under control? British Poultry Science, 51, 1-11.

Juhasz, K. \& Easton, A.J. (1994). Extensive sequence variation in the attachment (G) protein gene of avian pneumovirus: evidence for two distinct subgroups. The Journal of General Virology, 75, 2873-2880. 
Larkin, M.A., Blackshields, G., Brown, N.P., Chenna, R., McGettigan, P.A., McWilliam, H., Valentin, F., Wallace, I.M., Wilm, A., Lopez, R., Thompson, J.D., Gibson, T.J. \& Higgins, D.G. (2007). Clustal W and Clustal X version 2.0. Bioinformatics, 23, 2947-2948.

Lupini, C., Cecchinato, M., Ricchizzi, E., Pesente, P., Sperati Ruffoni, L. \& Catelli, E. (2010). Discriminazione rapida fra ceppi vaccinali e di campo di Metapneumovirus aviare mediante tecnica RFLP. In Atti del XLVIX Convegno annuale della Società Italiana di Patologia Aviare (pp. 177-180). Forlì, Italy.

Moreno, A., Piccirillo, A., Mondin, A., Morandini, E., Gavazzi, L. \& Cordioli, P. (2010). Epidemic of Infectious Laryngotracheitis in Italy: characterization of virus isolates by polymerase chain reaction - restriction fragment length polymorphism (PCR-RFLP) and sequence analysis. Avian Diseases, 54, 11721177.

Naylor, C.J., Brown, P.A., Edworthy, N., Ling, R., Jones, R.C., Savage, C.E. \& Easton, A.J. (2004). Development of a reverse-genetics system for avian pneumovirus demonstrates that the small hydrophobic $(\mathrm{SH})$ and attachment (G) genes are not essential for virus viability. Journal of General Virology, 85, 3219-3227.

Naylor, C.J. \& Jones, R.C. (1994). Demonstration of a virulent subpopulation in a prototype live attenuated turkey rhinotracheitis vaccine. Vaccine, 12, 12251230.

Oldoni, I., Rodriguez-Avila, A., Riblet, S.M., Zavala, G. \& Garcia, M., (2009). Pathogenicity and growth characteristics of selected infectious laryngotracheitis virus strains from the United States. Avian Pathology, 38, 47-53. 
Ongor, H., Karahan, M., Kalin, R., Bulut, H. \& Cetinkaya, B. (2010). Detection of avian metapneumovirus subtypes in turkeys using RT-PCR. The Veterinary Record, 166, 363-366.

Pringle, C.R. (1998). Virus taxonomy--San Diego 1998. Archives of Virology, 143, 1449-1459.

Reed, L.J. \& Muench, H. (1938). A simple method of estimating fifty percent end points. American Journal of Hygiene, 27, 493-497.

Seal, B.S., Sellers, H.S. \& Meinersmann, R.J. (2000). Fusion protein predicted amino acid sequence of the first US avian pneumovirus isolate and lack of heterogeneity among other US isolates. Virus Research, 66, 139-147.

Terregino, C. (2010). Le principali patologia respiratorie (e non) del $2009-\mathrm{I}^{\circ}$ quadrimestre 2010. XLIX Convegno annuale della Società Italiana di Patologia Aviare, Forlì, Italy. Available at: www.patologiaviare.org/hipgimmaginegrande.php?HIGNIdFile $=972$

Van de Zande, S., Nauwynck, H., Naylor, C. \& Pensaert, M. (2000). Duration of cross-protection between subtypes A and B avian pneumovirus in turkeys. The Veterinary Record, 147, 132-134.

Seal, B.S., Sellers, H.S. \& Meinersmann, R.J. (2000). Fusion protein predicted amino acid sequence of the first US avian pneumovirus isolate and lack of heterogeneity among other US isolates. Virus Research, 66, 139-147. 
Table 1. Nucleotide sequences of partial G gene of subtype A aMPVs. Vaccine 1 sequence is shown in full and other residues are only specified where different from this sequence.

Vaccine 1, IT/Ty/A/259-01/03 and 309/04 strains possess an exclusive cytosine residue at genome position 6358 which is a uracil in all other comparator strains.

\begin{tabular}{|c|c|}
\hline \multirow[b]{3}{*}{ Subtype aMPV strains } & Genome positions \\
\hline & $6355 \quad 6360$ \\
\hline & ............ \\
\hline Vaccine 1 & UGGUUUCGAUUGU \\
\hline $309 / 04$ & ............... \\
\hline IT/Ty/A/259-01/03 & ................... \\
\hline Vaccine 2 & .......U...... \\
\hline UK\#8544 & .......U....... \\
\hline CVL/14/1 & .......U....... \\
\hline LAH & .......U...... \\
\hline TRT/UK & ......U....... \\
\hline 1556 & ......U....... \\
\hline aMPV/A/Brazil/07/USP/03 & .......U....... \\
\hline aMPV/A/Brazil/05/USP/01 & ......U....... \\
\hline chicken/A/BR/119/95 & ......U....... \\
\hline chicken/A/BR/121/95 & .......U....... \\
\hline aMPV/chicken/Nigeria/NI389/2006 & ......U....... \\
\hline Brazil & .......U....... \\
\hline SHSBR662/03 & ......U....... \\
\hline SHSBR668/03 & ......U....... \\
\hline SHSBR669/03 & .......U...... \\
\hline
\end{tabular}


Table 2. Comparison of the nucleotide and amino acid sequences of aMPVs subtype A IT/Ty/A/259-01/03, vaccine 1 subtype A and vaccine progenitor (UK\#8544).

\begin{tabular}{|c|c|c|c|c|c|c|c|}
\hline \multirow{2}{*}{$\begin{array}{l}\text { Genome } \\
\text { Positions }\end{array}$} & \multirow[b]{2}{*}{ Region of genome } & \multicolumn{3}{|c|}{ Nucleotide } & \multicolumn{3}{|c|}{ Coded amino acid } \\
\hline & & UK\#8544 & Vaccine 1 & $\begin{array}{r}\text { IT/Ty/A/ } \\
259-01 / 03\end{array}$ & UK\#8544 & Vaccine 1 & $\begin{array}{l}\text { IT/Ty/A/ } \\
259-01 / 03\end{array}$ \\
\hline 1932 & $P$ & $\mathrm{C}$ & $\mathrm{C}$ & $\mathrm{A}^{\mathrm{b}}$ & A & $\mathrm{A}$ & $\mathrm{E}^{\mathrm{c}}$ \\
\hline 2197 & M & $\mathrm{C}$ & $\mathrm{C}$ & $A^{b}$ & S & S & $\mathrm{Y}^{\mathrm{c}}$ \\
\hline 2941 & Transcriptionstart & G & A & A & none $^{\mathrm{d}}$ & none & none \\
\hline 3553 & $\mathrm{~F}$ & $\mathrm{U}$ & $\mathrm{C}$ & $\mathrm{U}$ & $\mathrm{V}$ & A & V \\
\hline 3825 & $\mathrm{~F}$ & $\mathrm{C}$ & A & A & $\mathrm{E}$ & K & K \\
\hline 5055 & M2 & A & G & G & K & $\mathrm{R}$ & $\mathrm{R}$ \\
\hline 5140 & M2 & $\mathrm{U}$ & $\mathrm{C}$ & $\mathrm{C}$ & $\mathrm{V}$ & $\mathrm{N}$ & $\mathrm{N}$ \\
\hline 5929 & SH-G intergenic & A & $\mathrm{G}$ & G & none & none & none \\
\hline 6358 & $\mathrm{G}$ & $\mathrm{U}$ & $\mathrm{C}$ & $\mathrm{C}$ & $\mathrm{F}$ & $\mathrm{F}$ & $\mathrm{F}$ \\
\hline 7069 & G & $\mathrm{U}$ & $\mathrm{U}$ & $C^{b}$ & Y & $\mathrm{Y}$ & $\mathrm{Y}$ \\
\hline 8766 & $\mathrm{~L}$ & $\mathrm{C}$ & $\mathrm{C}$ & $\mathrm{U}^{\mathrm{b}}$ & $\mathrm{L}$ & $\mathrm{L}$ & $\mathrm{L}$ \\
\hline 10022 & $\mathrm{~L}$ & $\mathrm{U}$ & G & G & V & $\mathrm{V}$ & V \\
\hline 11624 & $\mathrm{~L}$ & $\mathrm{U}$ & $\mathrm{C}$ & $\mathrm{C}$ & $\mathrm{Y}$ & $\mathrm{Y}$ & $\mathrm{Y}$ \\
\hline
\end{tabular}

${ }^{\text {a }}$ Antigenome sense.

${ }^{\mathrm{b}}$ Nucleotide mutations additional to vaccine markers, unique to strain IT/Ty/A/259-01/03.

${ }^{\mathrm{c}}$ Amino acid mutations unique to strain IT/Ty/A/259-01/03.

${ }^{\mathrm{d}}$ Non coding regions. 
Figure 1. Phylogenetic tree based on the alignment of nucleotide sequences (268 bp) of partial G genes of subtype A aMPVs constructed using Neighbor Joining method and bootstrap analysis (1,000 replicates) by MEGA 4 software. Strain IT/Ty/A/259-01/03 forms a separate cluster containing Vaccine 1 and the 309/04 strain. The bootstrap value is indicated at the left of the supported node.

Figure 2. Mean daily clinical scores following inoculation of 1-day-old poults with aMPV isolate IT/Ty/A/259-01/03, vaccine 1 or sterile water at 1-day-old. 


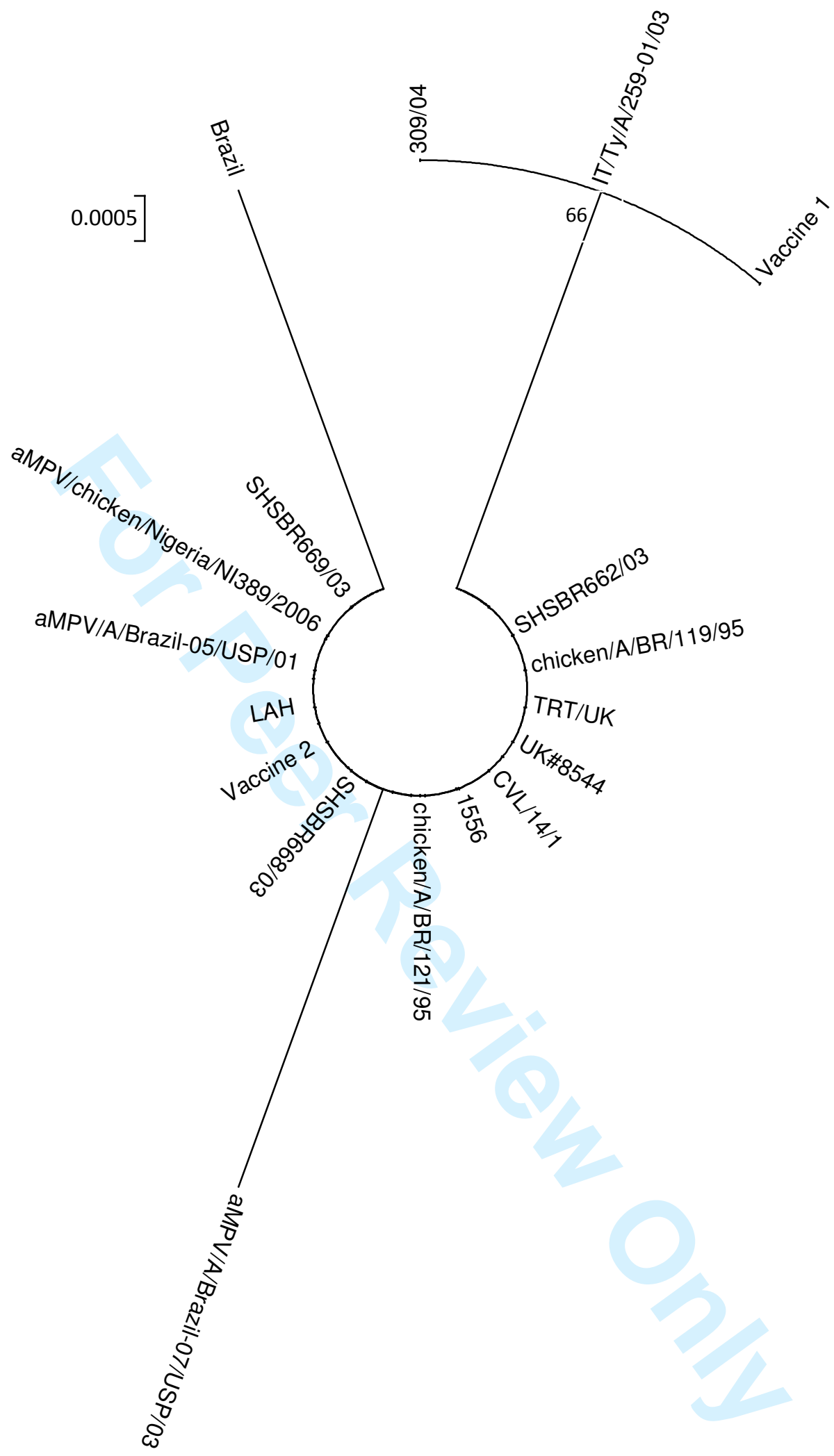

Figure 1. Phylogenetic tree based on the alignment of nucleotide sequences ( $268 \mathrm{bp}$ ) of partial $\mathrm{G}$ genes of subtype A AMPVs constructed using Neighbor Joining method and bootstrap analysis $(1,000$ replicates) by MEGA 4 software. Strain IT/Ty/A/259-01/03 form a separate cluster containing Vaccine 1 and 309/04 strain. The bootstrap value is indicated at the left of the supported node. 


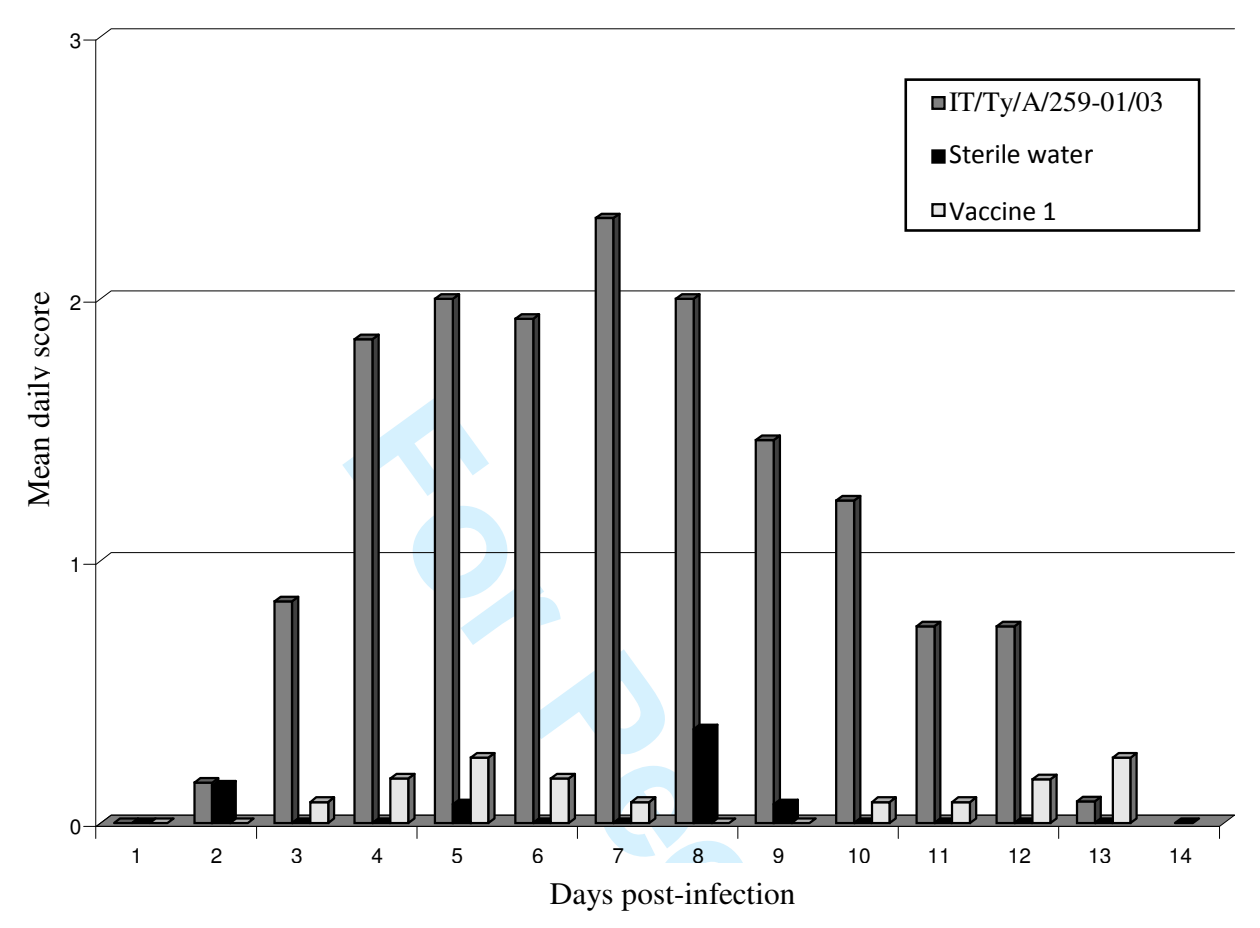

Figure 2. Mean daily clinical scores following inoculation of 1-day-old poults of isolate IT/Ty/A/259-01/03, vaccine 1 and sterile water. 